\title{
Corrected Transposition of the Great Arteries with Ebstein's Anomaly, Dysplasia of the Mitral Leaflets and Persistence of Left Superior Vena Cava in an Adult
}

\author{
Aureo Campos-Tello1 ${ }^{*}$, Giancarlo A. Valle1, Luis M. Milla1, Angel D. Cueva1, Sara Ramirez-Flores ${ }^{1}$, \\ Oscar García-Rosadio', Pablo A. Mendoza², Nilda Espinola-Zavaleta ${ }^{3}$ \\ ${ }^{1}$ Department of Cardiology, Hospital Nacional Dos de Mayo, Lima, Peru \\ ${ }^{2}$ Department of Electrophysiology, Hospital Nacional Dos de Mayo, Lima, Peru \\ ${ }^{3}$ Department of Nuclear Cardiology, National Institute Ignacio Chavez, Mexico City, Mexico \\ Email: *afernandocampos@gmail.com
}

How to cite this paper: Campos-Tello, A., Valle, G.A., Milla, L.M., Cueva, A.D., Ramirez-Flores, S., García-Rosadio, O., Mendoza, P.A. and Espinola-Zavaleta, N. (2020) Corrected Transposition of the Great Arteries with Ebstein's Anomaly, Dysplasia of the Mitral Leaflets and Persistence of Left Superior Vena Cava in an Adult. World Journal of Cardiovascular Diseases, 10, 50-56. https://doi.org/10.4236/wjcd.2020.102006

Received: January 10, 2020

Accepted: February 10, 2020

Published: February 13, 2020

Copyright $\odot 2020$ by author(s) and Scientific Research Publishing Inc. This work is licensed under the Creative Commons Attribution International License (CC BY 4.0).

http://creativecommons.org/licenses/by/4.0/ (c) (i) Open Access

\begin{abstract}
Introduction: Congenitally corrected transposition of the great arteries (cc-TGA) is a congenital heart disease rarely described among adult population, especially if it is associated with other abnormalities such as Ebstein's anomaly and abnormal origin of coronary arteries. Case presentation: Twenty-two-year-old woman admitted to intensive care unit with acute decompensated heart failure. The transthoracic echocardiography demonstrated atrioventricular and ventriculoarterial discordance. The left-sided atrioventricular valve, in this case, the tricuspid valve, showed apical displacement of the septal valve suggesting Ebstein's anomaly. The computed tomography corroborated these findings and additionally showed a left superior vena cava and an abnormal origin of the coronary arteries. The patient is in NYHA functional class II, receiving treatment with diuretic, digitalis, beta-blockers and angiotensin-converting enzyme (ACE) inhibitor. Conclusion: This is a very interesting case of an adult in the third decade of life with cc-TGA associated with abnormalities not described in the literature that had reached adulthood. Noninvasive images play an important role in its diagnosis.
\end{abstract}

\section{Keywords}

Corrected Transposition, Echocardiography, Ebstein's Anomaly, Computed Tomography 


\section{Introduction}

The incidence of grown up congenital heart disease is still unknown. According to the $32^{\text {nd }}$ Bethesda Conference reported in 2000, there were approximately 2800 adults with congenital heart disease (CHD) per 1 million population, with more than half of them having moderate or high complexity of their defect [1].

Congenitally corrected transposition of the great arteries (cc-TGA or L-TGA) is an uncommon entity, accounting for $<1 \%$ of all CHD [2]. The commonest associated defect is ventricular septal defect, found in two-thirds of cases, followed by stenosis of the outflow tract of the morphologically left ventricle found in $50 \%$. Tricuspid valve is abnormal with varying degrees of apical displacement into the ventricular cavity resembling Ebstein's anomaly [3]. According to the literature, there are few reports of L-TGA associated with Ebstein's anomaly in adult population, given that the majority of patients die within the first years of life if they are not surgically treated. We present a rare case of an adult woman with L-TGA associated with Ebstein's anomaly, left superior vena cava and pulmonary hypertension diagnosed by non-invasive imaging and computed tomography.

\section{Case Presentation}

A 22-year-old-woman from Ayacucho-Peru came to her local hospital with signs of systemic and pulmonary congestion. The patient was initially managed with inotropic and vasopressor drugs, diuretic therapy and high flow oxygen and then was referred to our hospital. She was hospitalized in the intensive care unit with tachycardia (heart rate: $101 \mathrm{bpm}$ ), tachypnea (respiratory rate: $24 / \mathrm{min}$ ), hypotension (BP: 92/62 $\mathrm{mmHg}$ ) and blood oxygen saturation of $98 \%\left(\mathrm{FiO}_{2} 36 \%\right)$. At physical exam, signs of systemic and pulmonary congestion, with painful hepatomegaly, jugular ingurgitation and edema in lower limbs and bi-basal rales were found. On auscultation, the heart sounds were arrhythmic, with an increased second cardiac sound, systolic murmur III/VI in mitral focus and systolic murmur IV/VI in tricuspid focus. Electrocardiogram in sinus rhythm with heart rate of $75 \mathrm{bpm}$. QS wave in DII, DIII, aVF and RS wave from V2 - V6 (Figure 1). Chest X-ray showed a severe cardiomegaly and signs of pulmonary congestion. The transthoracic echocardiogram demonstrated situs solitus in levocardia. Ostium secundum atrial septal defect of $1.1 \mathrm{~cm}$ with left to right shunt, great vessels side to side, the pulmonary artery located to the right and aorta to the left. In four-chamber view, atrioventricular discordance was detected with severe tricuspid regurgitation (vena contracta $=9.3 \mathrm{~mm}$ ) and dysplasia of the mitral leaflets with severe mitral regurgitation (vena contracta $=10.3 \mathrm{~mm}$ ) by color Doppler, Video 1 . The septal leaflet of the tricuspid valve was apically displaced (1.8 $\mathrm{cm} / \mathrm{m}$ ); with septal leaflet attachment ratio (SLAr) of 0.26, indicating mild Ebstein's anomaly. The systemic ventricle's ejection fraction was $40 \%$ (calculated by simpson's method). The pulmonary ventricle's systolic function evaluated by $\mathrm{dP} / \mathrm{dT}$ of mitral regurgitation was $757 \mathrm{mmHg} / \mathrm{sec}$. The systolic pulmonary artery pressure was $60 \mathrm{mmHg}$. Also, ventriculoarterial discordance was detected 


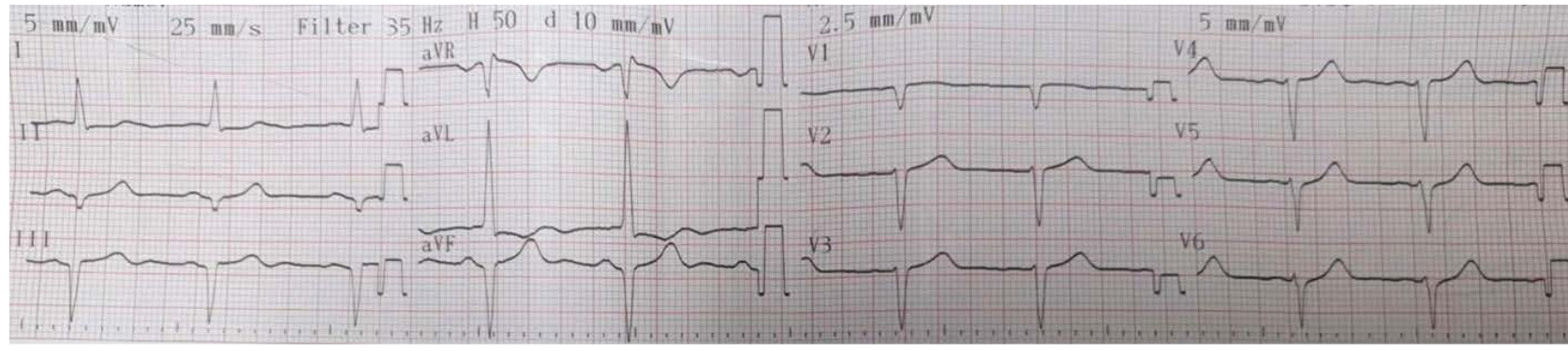

Figure 1. Electrocardiogram in sinus rhythm with heart rate of $75 \mathrm{bpm}$. QS wave in DII, DIII, aVF and RS wave from V2 - V6.

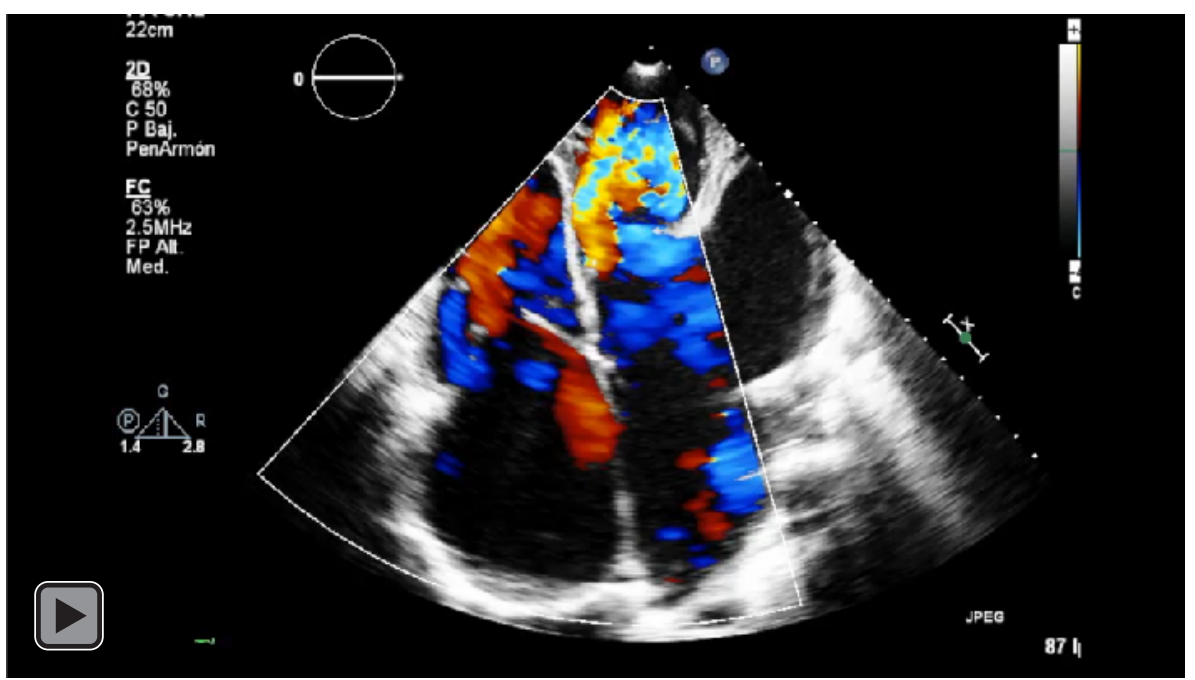

Video 1. Bidimensional and color Doppler four chamber view showing the atrioventricular discordance and severe regurgitation of atrioventricular valves.

with aorta anterior and to the left and pulmonary artery posterior and to the right, Figure 2. Persistence of left superior vena cava (SVC) connected to the right SVC by an innominate vein was found. The aortic arch is left-sided, without obstructions.

The computed tomography corroborated the double discordance with Ebstein's anomaly, ostium secundum atrial septal defect with diameter of $1.14 \mathrm{~cm}$ and persistence of the left superior vena cava. The aortic arch and the thoracic descending aorta are normal. The right coronary artery origins from the non-coronary cusp and the left main coronary artery from the right coronary cusp, Figure 3.

The patient is receiving treatment with diuretics, digoxin, beta-blockers and angiotensin converting enzyme (ACE) inhibitors with improvement of her symptoms.

He is currently in NYHA functional class II with a follow-up every 2 months at the Congenital Heart Disease Adult Clinic of our institution.

\section{Discussion}

Congenitally corrected transposition of great arteries (cc-TGA) accounts for $0.5 \%$ of all CHD [4]. It is commonly associated with ventricular septal defect in 


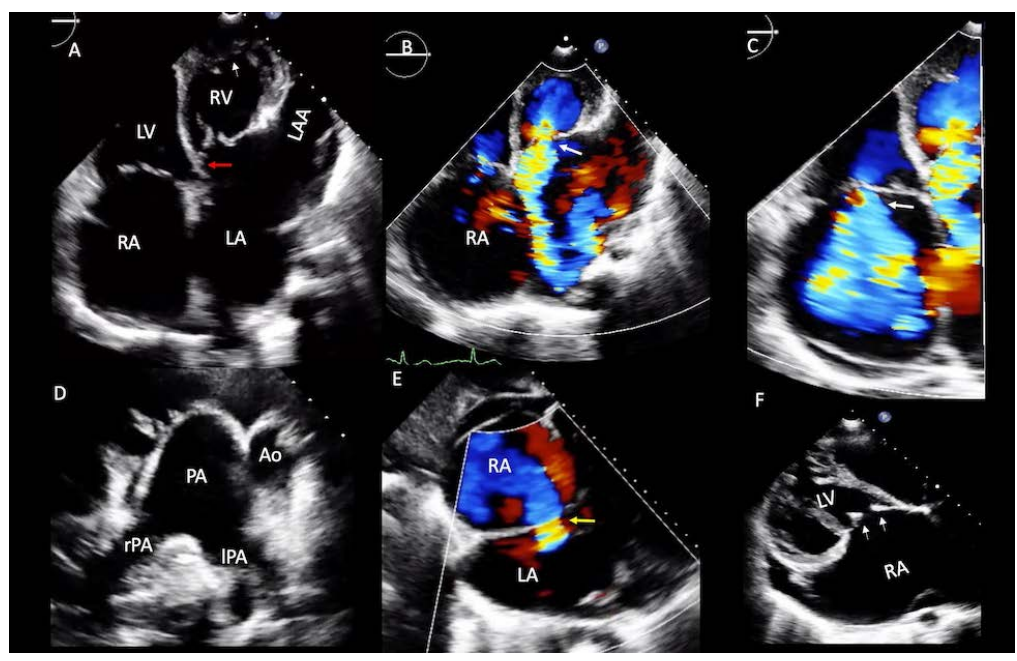

Figure 2. (A) In the apical four-chamber view an atrioventricular discordance is observed, the left-sided ventricle has a moderator band (white arrow) and displacement of the septal leaflet of the tricuspid valve $\left(1.8 \mathrm{~cm} / \mathrm{m}^{2}\right)$ suggesting mild Ebstein's anomaly (SLAr: 0.26) red arrow. (B) Severe tricuspid regurgitation (white arrow). (C) Severe mitral regurgitation (white arrow). (D) Short axis parasternal view showing ventriculoarterial discordance with great vessels side to side, the aorta is anterior and to the left of the pulmonary artery is posterior and to the right. (E) Four chamber subcostal view with color flow showing ostium secundum atrial septal defect of $1.1 \mathrm{~cm}$ (yellow arrow). (F) Bidimensional four chamber view with dysplasia of the mitral leaflets (white arrows). Abbreviations: RA-right atrium; RV-right ventricle; LA-left atrium; LV-left ventricle; PA-pulmonary artery; rPA-right pulmonary artery; lPA-left pulmonary artery; LAA-left atrial appendage.

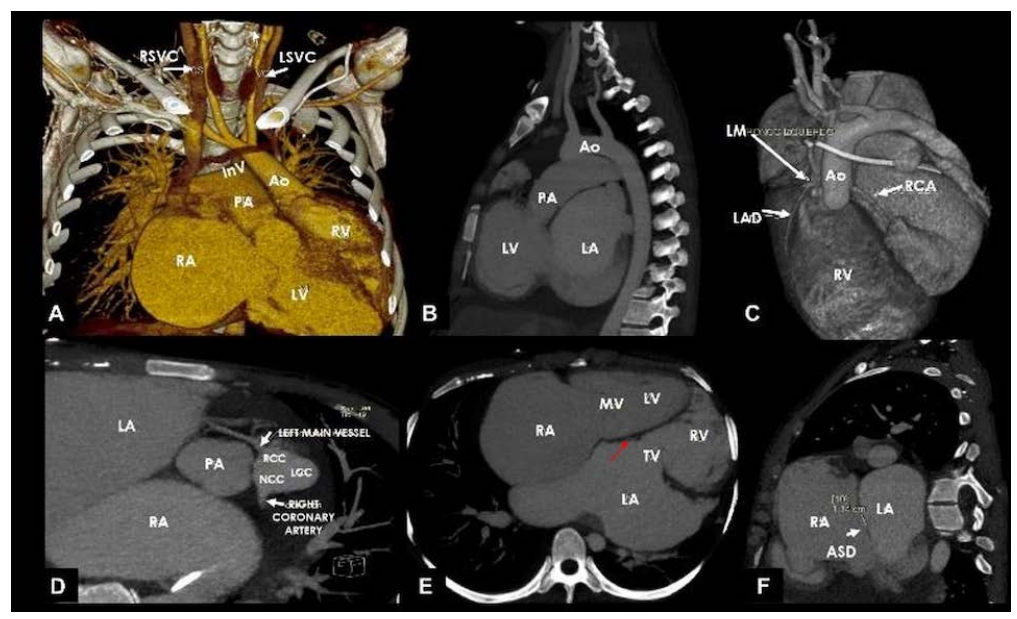

Figure 3. (A) Double discordance with great arteries side to side, left SVC (white arrow) connected to the right SVC by an innominate vein. (B) The aortic arch is left sided and the thoracic descending aorta is normal. (C, D) The left main coronary artery (white arrow) is emerging from the right coronary sinus and the right coronary artery from the noncoronary sinus. (E) Atrioventricular discordance and displacement of the septal leaflet of the tricuspid valve with (red arrow) a SLAr of 0.32, suggesting a mild Ebstein's anomaly, (red arrow). (F) Ostium secundum atrial septal defect of $1.14 \mathrm{~cm}$, (white arrow). Abbreviations as before. RSVC-right superior vena cava; LSVC-left superior vena cava; LM-Left main coronary artery; RCA-right coronary artery; LAD-left anterior descending artery; RCC-right coronary cusp; NCC-non coronary cusp; LCC-left coronary cusp; $\mathrm{MV}$-mitral valve; ASD-atrial septal defect; In V-innominate vein. 
the $60 \%$ to $80 \%$ of cases, pulmonary stenosis or atresia in $30 \%$ to $50 \%$ and abnormalities of tricuspid valve with varying degrees of tricuspid regurgitation in $14 \%$ to $56 \%$ [4]. However, it is rarely associated with an authentic Ebstein anomaly and persistence of the left superior vena cava that drains into the azygos vein. The persistence of left superior vena cava (SVC) is a rare congenital anomaly and can be seen in conjunction with other cardiac or vascular abnormalities. Identification of inferior vena cava with azygos continuation is of great importance before catheterization access from the femoral veins and any surgical procedures to complex congenital heart disease [5]. In fact, Celermajer et al. over a 20-year period from 1968 to 1988 found 10 cases with coexisting cc-TGA and Ebstein's anomaly; none of them had left SVC. Unlike our patient who has reached adulthood, those patients were neonates ( 7 cases) or children ( 3 cases) and 5 of them die within first year of life; these patients had severe systemic atrioventricular valve regurgitation and aortic arch obstruction [6]. On the other hand, pulmonary hypertension is rare in the absence of a large ventricular septal defect [4]. In our case, despite no ventricular septal defect, a moderate pulmonary hypertension was detected, probably as a result of the volume overload due to severe tricuspid regurgitation. Also, severe mitral regurgitation caused by dysplasia of the mitral leaflets was evident, which is a less common condition associated with cc-TGA [4]. Mitral valve straddling occurs in hearts with double inlet ventricles or a double outlet RV, criss-cross hearts and in some rare cases of ccTGA [7] [8] [9]. As described in literature, our patient had situs solitus atrial (like $95 \%$ of cases) and normal heart position (nearly $80 \%$ of cases are in levocardia) [4]. The relationship of the great vessels showed a distinct pattern to the usual, the great vessels were in parallel or side to side [3].

With regard to the possibilities of surgical treatment we must emphasize that this type of complex CHD is rarely seen in adults, so there is quite few expertise in repairing this type of defects in our country. However, in experienced centers, if the ejection fraction is depressed despite afterload therapy [4], options such as the double switch operation or transplantation should be considered [3]. When the systemic ventricle shows depressed systolic function and severe tricuspid regurgitation, and the double-switch procedure is not feasible, one alternative in the adult age group is the systemic atrioventricular replacement with an acceptable perioperative mortality. Between 1964 and 1993, 40 patients with cc-TGA underwent systemic atrioventricular replacement. The survival was $78 \%$ at 5 years and $61 \%$ at 10 years. Most deaths were due to systemic ventricular dysfunction; being the ejection fraction $>45 \%$ a predictor of survival [3] [4]. However, according to Yeh et al. who reported a series of 127 patients with cc-TGA who underwent surgery, the reoperation rate was $80 \%$ for tricuspid valve replacement [4]. Given the lack of experienced centers to perform a double-switch procedure or cardiac transplant a reasonable approach could be the systemic atrioventricular replacement for recovery of the systemic ventricular function because reduction of the fluid overload due to tricuspid regurgitation. 


\section{Conclusions}

This patient has certain features that are common to the usual presentation of cc-TGA, but there are no current reports of cc-TGA associated with authentic Ebstein's anomaly, dysplasia of the mitral leaflets, left SVC and pulmonary hypertension, being even more interesting the fact that the patient reached adulthood.

Non-invasive images (echocardiography and computed tomography) played a very important role in the precise characterization of this complex congenital heart disease.

\section{Conflicts of Interest}

The authors declare no conflicts of interest regarding the publication of this paper.

\section{References}

[1] Warnes, C.A., Liberthson, R., Danielson, G.K., Dore, A., Harris, L., Hoffman, J.I., et al. (2001) Task Force 1: The Changing Profile of Congenital Heart Disease in Adult Life. Journal of the American College of Cardiology, 37, 1170-1175. https://doi.org/10.1016/S0735-1097(01)01272-4

[2] Baumgartner, H., Bonhoeffer, P., De Groot, N.M.S., de Haan, F., Deanfield, J.E., Galie, N., et al. (2010) The Task Force on the Management of Grown-Up Congenital Heart Disease of the European Society of Cardiology. ESC Guidelines for the Management of Grown-Up Congenital Heart Disease. European Heart Journal, 31, 2915-2957.

[3] Brawn, W., Jones, T., Anderson, R. and Barron, D. (2010) Congenitally Corrected Transposition. In: Anderson, R., et al. (Eds.), Pediatric Cardiology, 3rd Edition, Churchill Livingstone, Philadelphia, 818-835.

https://doi.org/10.1016/B978-0-7020-3064-2.00042-4

[4] Graham, T. and Markham, L. (2011) Congenitally Corrected Transposition of the Great Arteries. In: Webb, G. and Daubeney, P., (Eds.), Diagnosis and Management of Adult Congenital Heart Disease, 2nd Edition, Elsevier, Philadelphia, 371-377. https://doi.org/10.1016/B978-0-7020-3426-8.00049-6

[5] Paterick, T.E., Schmidt, M., Jan, M.F., Kramer, C., Umland, M.M., Bloomgarden, D., et al. (2012) Congenitally Corrected Transposition of the Great Arteries with Anomalous Inferior Vena Cava Drainage: Multimodality Imaging. Echocardiography, 29, E16-E19. https://doi.org/10.1111/j.1540-8175.2011.01516.x

[6] Celermajer, D.S., Cullen, S., Deanfield, J.E. and Sullivan, I.D. (1991) Congenitally Corrected Transposition and Ebstein's Anomaly of the Systemic Atrioventricular Valve: Association with Aortic Arch Obstruction. JACC, 18, 1056-1058. https://doi.org/10.1016/0735-1097(91)90766-3

[7] Kurosawa, H., Imai, Y. and Becker, A.E. (1990) Congenitally Corrected Transposition with Normally Positioned Atria, Straddling Mitral Valve, and Isolated Posterior Atrioventricular Node and Bundle. Journal of Thoracic and Cardiovascular Surgery, 99, 312-313. https://doi.org/10.1016/S0022-5223(19)37016-3

[8] Wenink, A.C.G. and Gittenbergerdegroot, A.C. (1982) Straddling Mitral and Tricuspid Valves: Morphologic Differences and Developmental Backgrounds. American Journal of Cardiology, 49, 1959-1971. 
https://doi.org/10.1016/0002-9149(82)90216-8

[9] Chin, T.K., Santulli, T.V., Laks, H.L. and Williams, R.G. (1988) Diagnosis and Management of Straddling Mitral Valve. American Journal of Cardiology, 62, 505. 